\title{
Photographic identification of sea turtles: method description and validation, with an estimation of tag loss
}

\author{
Júlia Reisser ${ }^{1, *}$, Maíra Proietti ${ }^{1}$, Paul Kinas ${ }^{2}{ }_{\text {, Ivan Sazima }}{ }^{3}$ \\ ${ }^{1}$ Instituto de Oceanografia, and ${ }^{2}$ Instituto de Matemática, Estatística e Física, Universidade Federal do Rio Grande (FURG), \\ Caixa Postal 474, Av. Itália km 8, 96201-300 Rio Grande, Rio Grande do Sul, Brazil \\ ${ }^{3}$ Museu de Zoologia, CP 6109, Universidade Estadual de Campinas, 13083-970 Campinas, São Paulo, Brazil
}

\begin{abstract}
Recognition of individual sea turtles is mostly achieved by checking artificial tags previously attached to them, a method which is made difficult by the considerable tag loss rate and which requires repeated manipulation of the marked individuals. We describe an individual recognition method for sea turtles of the family Cheloniidae based on a mark-recapture study that relied on both artificial tagging (Inconel tags, style 681) and natural marks (facial profile photographs). Juvenile green Chelonia mydas and hawksbill Eretmochelys imbricata turtles were manually caught at Arvoredo Island, southern Brazil, and through visual comparison of facial profile photographs we were able to identify recaptured individuals with 2, 1 , or no artificial tags. Additionally, Bayesian inference based on tag loss information indicated that the way a tag is attached (position and distance from the flipper edge) affects significantly the probability of its loss. We encourage the use of photographic identification (facial profile) as a reliable method for individual recognition in studies of cheloniid turtles.
\end{abstract}

KEY WORDS: Photo-identification $\cdot$ Sea turtles $\cdot$ Cheloniidae $\cdot$ Tag loss $\cdot$ Bayesian inference Resale or republication not permitted without written consent of the publisher

\section{INTRODUCTION}

Recognition of individuals within a population is a key issue for most behavioral and ecological studies of wild animals. Capture-recapture data can be used for a number of questions of biological interest and conservation relevance. For sea turtles, individual recognition is frequently achieved through the attachment of easy-to-read tags (metal or plastic), usually attached on the front flippers of intentionally or accidentally caught individuals (Balazs 1999). However, marking animals generally involves capture and handling, which may result in injury to the animal and is difficult with large individuals and populations. Moreover, loss rates of marks are an important variable to be considered in any mark-recapture study that aims to estimate growth rate, survivorship, residency, movements, foraging patterns, reproductive biology, stranding, population size, social organization, and demographics. Consider- ing the long duration of sea turtle life cycles, the loss rate of artificial tags is notoriously high and varies due to several factors, such as time after tag attachment, tagger, study area, target species, animal size, piercing site, tag material, color and design (Balazs 1982, Mrosovsky \& Shettleworth 1982, Limpus 1992, Bjorndal et al. 1996, van Dam \& Diez 1999, Bellini et al. 2001). Presently, many sea turtle studies are limited by lack of accurate estimates of tag loss probability or by difficulty in longterm identification of individuals.

Although artificial marking was considered almost a prerequisite for behavioral work in the past, increasing numbers of studies of wild animals, especially after 1970, have shown that various vertebrates can be reliably identified through natural marks. Photographic identification (photo-ID) is an approach that utilizes photographs/films of conspicuous features on the animal's body or footprints to aid in its individual recognition (Table 1). The non-intrusive nature of photo-ID is 
particularly advantageous in studies of threatened and endangered species, among which all species of sea turtles are included (see the International Union of Conservation of Nature 2007, Red List of Threatened Species: www.iucnredlist.org). However, this method is not always error-proof, since individuals may have similar and mutable marking patterns, leading to errors in distinguishing individuals (false positives) or multiple identifications of the same individual (false negatives). Also, poor-quality photographs decrease match success by increasing the probability of missing a match (Kelly 2001, Speed et al. 2007). Evaluation of the efficiency of a new photo-ID technique may be achieved through studies combining this technique with various sorts of tagging (Hammond et al. 1990).

Digital technology is enhancing and advancing photo-ID research, not only due to easy acquisition of high-resolution digital photographs, which make the method more efficient (Markowitz et al. 2003), but also due to the possibility of developing several fast and instrumental computer-assisted matching schemes that significantly decrease the number of images in the database to be analyzed by a researcher. Although the volume published by the International Whaling Commission (IWC) in 1990 was a landmark in the field of computer identification, new developments in computer technology and capability have been substantial thereafter (Kelly 2001). The European project EUROPHLUKES (www.europhlukes.net) is an example of recent efforts in the development of photo-ID automation for matching flukes and dorsal fins.

Despite the advantages of photo-ID, such as minimized manipulation of the animals, increase in efficiency of individual records and reduction of problems due to tag loss, efforts to develop photo-ID techniques for sea turtles are almost non-existent. Individual recognition through comparison of coloration patterns on the head of leatherback turtles Dermochelys coriacea is the only published case of which we are aware (McDonald \& Dutton 1996). For cheloniids, we found only 1 study (published in a symposium), utilizing underwater photographs of Hawaiian green turtle facial profiles for photo-ID of individuals frequently observed during scuba dives (Bennett et al. 2000).

In the present study, we deal with (1) description and validation of a method for photo-ID using facial scute

Table 1. Some natural marks used to identify species at individual levels. The column 'Main sources' contains references to recent surveys that used the corresponding natural mark in different animal groups; it also presents a brief description of the photo-identification techniques applied to the studied species

\begin{tabular}{|c|c|c|}
\hline Natural mark type & Main sources & \\
\hline \multirow[t]{6}{*}{ Color patterns } & Mammal (terrestrial) & $\begin{array}{l}\text { Kelly (2001): a } 3 \text {-D computer-aided matching for pelage spot patterns on } \\
\text { flanks of Serengeti cheetahs Acinonyx jubatus. The study indicates that the } \\
\text { technique may be applied to other animals that have complex and variable } \\
\text { pelage patterns. }\end{array}$ \\
\hline & Mammals (marine) & $\begin{array}{l}\text { Hammond et al. (1990): a 3-D model to describe pelage and other patterns on } \\
\text { the head and neck of gray seals Halichoerus grypus and manual matches } \\
\text { based on, for example, (1) presence or absence of spots in various body areas } \\
\text { in harbor seals Phoca vitulina, (2) mottling on back and flanks of blue whales } \\
\text { Balaenoptera musculus, (3) callosities on head of right whales Eubalaena aus- } \\
\text { tralis. }\end{array}$ \\
\hline & Bird & $\begin{array}{l}\text { Burghardt et al. (2004): a real-time system that extracts from video sequences } \\
\text { a unique biometrical identifier based on black spots pattern on chest of African } \\
\text { penguins Spheniscus demersus. }\end{array}$ \\
\hline & Reptile & $\begin{array}{l}\text { McDonald \& Dutton (1996): a manual matching based on patterns of pink spots } \\
\text { on head of leatherback turtles Dermochelys coriacea. }\end{array}$ \\
\hline & Fish & $\begin{array}{l}\text { Speed et al. (2007): an automated spot-recognition program }\left(\mathrm{I}^{3} \mathrm{~S}\right) \text { for matching } \\
\text { spot patterns in wild animals, applied to spot rows on flanks of whale sharks } \\
\text { Rhincodon typus. }\end{array}$ \\
\hline & Invertebrate & $\begin{array}{l}\text { Frisch \& Hobbs (2007): a manual matching based on pigmentation patterns on } \\
\text { the first abdominal sclerite of painted crayfish Panulirus versicolor. }\end{array}$ \\
\hline Footprints & Mammal (terrestrial) & $\begin{array}{l}\text { Alibhai et al. (2008): an automated footprint identification technique (FIT) that } \\
\text { extracted geometric profiles from digital images of footprints, applied to white } \\
\text { rhinoceroses Ceratotherium simum. }\end{array}$ \\
\hline \multirow[t]{3}{*}{ Contours } & Mammal (terrestrial) & $\begin{array}{l}\text { Project Elephind: www.leidenuniv.nl/cml/pmo/students/elephind/: an auto- } \\
\text { mated matching based on multi dimensional feature vectors that describes ear } \\
\text { contours of African elephants Loxodonta africana. }\end{array}$ \\
\hline & Mammals (marine) & $\begin{array}{l}\text { Gope et al. (2005): an automated match based on the area-of-mismatch } \\
\text { between lines that represent the edge of flippers of sea lions Eumetopias juba- } \\
\text { tus, as well as dorsal fins of dolphins or flukes of whales. }\end{array}$ \\
\hline & Shark & $\begin{array}{l}\text { Castro \& Rosa (2005): a manual matching based mainly on contours of the fins } \\
\text { of nurse sharks Ginglymostoma cirratum, extracted from underwater photos. }\end{array}$ \\
\hline
\end{tabular}


patterns in cheloniid turtles, and (2) formulation of a Bayesian model that allows estimation of tag loss and verification of the influence of different factors on these estimations. Data are from a 3 yr mark-recapture study of juvenile green and hawksbill turtles at Arvoredo Island, Brazil, Southwestern Atlantic.

\section{MATERIALS AND METHODS}

Arvoredo Island $\left(27^{\circ} 15^{\prime} \mathrm{S}, 48^{\circ} 25^{\prime} \mathrm{W}\right)$ lies within the $176000 \mathrm{~km}^{2}$ Arvoredo Marine Biological Reserve (Fig. 1). It is located $6.5 \mathrm{~km}$ east from the mainland, on the continental shelf of Santa Catarina state (southern Brazil) and includes several small islands (Gherardi 2004). In 9 expeditions to the study area, Chelonia mydas and Eretmochelys imbricata juveniles were manually caught during free and scuba dives.

The turtles were (1) measured-curved carapace length (CCL), curved carapace width (CCW), both taken with a flexible metric tape, and straight carapace length (SCL), straight carapace width (SCW), both taken with a wood caliper; (2) weighed with a Plenna $100 \mathrm{~kg}$-capacity tensile scale; (3) tagged with passive Inconel marks - style 681, manufactured by the
National Band and Tag Company (NBTC) and provided by the Projeto Tamar-ICMBio; and (4) photographed with digital cameras. Due to lack of tags, in the first expedition we were unable to mark turtles and thus we used photographic records only (Table 2). Tags were attached between the first and second scales of the front flippers (between scales, BS) until the third expedition; from the fourth expedition on, the piercing site was before the first scale of the same flippers (pre-scale, PS). In the BS tagging, the tag was attached so that about a one-half to one-third of the tag extended beyond the posterior edge of the flipper. In the PS tagging, the perforation area went further from the edge of the flipper, with the tag placed so that about one-third to none of the tag extended beyond the posterior edge. The through-the-hole lock of attached tags was always checked afterwards, to make certain that the point had locked fully into place. All recovered tags were checked for any anomalies (e.g. corrosion, biofouling), then cleaned of epibionts and removed if poorly retained or unreadable. The lost tags were always substituted and thus the turtle returned to sea double-tagged.

Photographs were standardized for all individuals: each profile was photographed from about $20 \mathrm{~cm}$ to

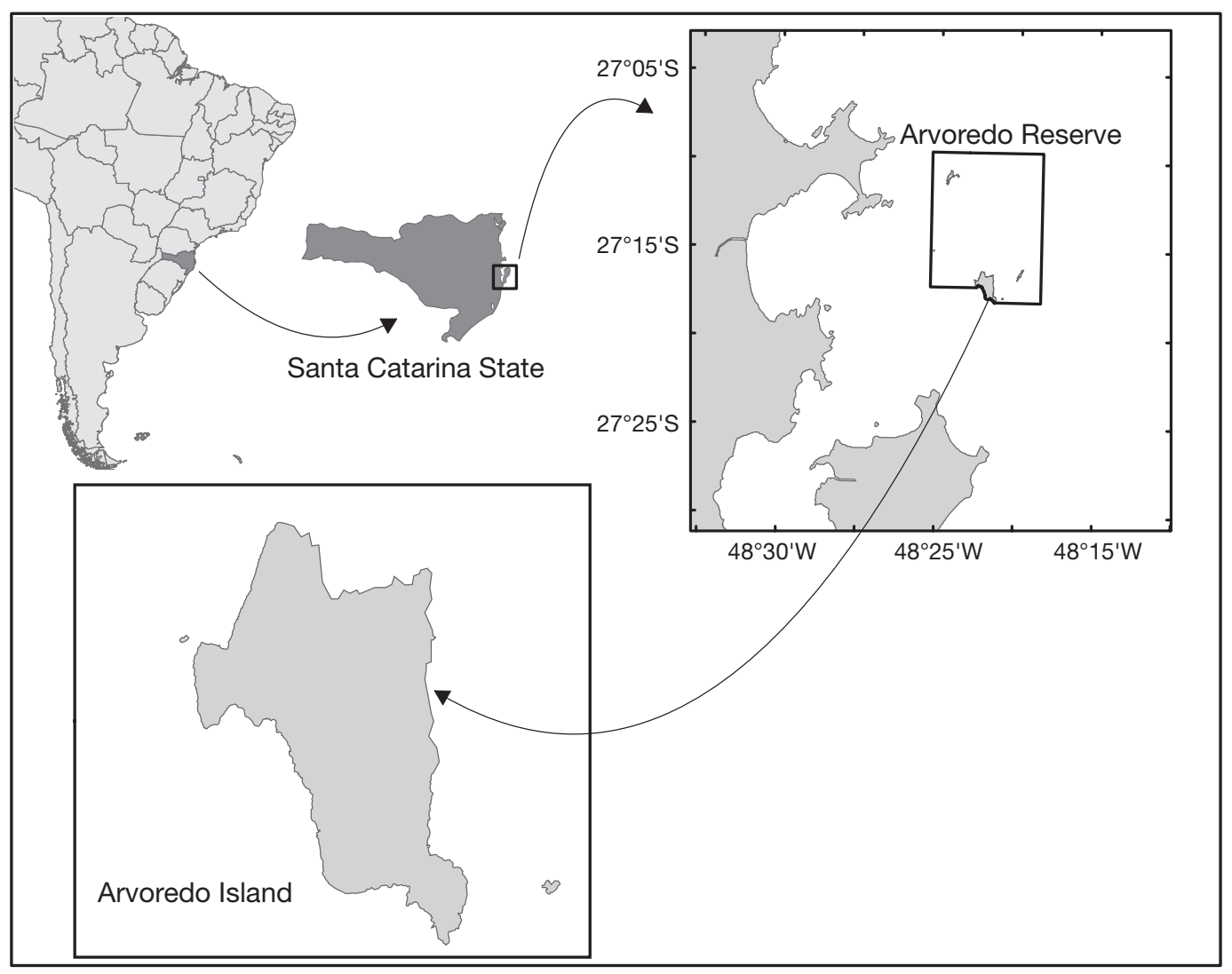

Fig. 1. Study area in the Southwestern Atlantic 
Table 2. Chelonia mydas and Eretmochelys imbricata. Selected data for 9 expeditions to Arvoredo Island, including dates, search hours, mean water temperature and visibility, as well as number of turtles successfully captured ( $\mathrm{N}_{\text {cap }}$ ), released with double tags $\left(\mathrm{N}_{\text {tag }}\right)$, and photographed $\left(\mathrm{N}_{\text {photo }}\right)$. Standard deviations and sample sizes (n expedition days with data collection) are given in parentheses

\begin{tabular}{|c|c|c|c|c|c|c|}
\hline Expedition & Search (h) & Water temperature $\left({ }^{\circ} \mathrm{C}\right)$ & Water visibility $(\mathrm{m})$ & $\mathrm{N}_{\text {cap }}$ & $\mathrm{N}_{\text {tag }}$ & $\mathrm{N}_{\text {photo }}$ \\
\hline Jan 2005 & 32 & $25.3(1.49 ; \mathrm{n}=12)$ & $9.0(1.42 ; \mathrm{n}=11)$ & 8 & 0 & 8 \\
\hline Mar 2005 & 23 & $26.4(0.55 ; \mathrm{n}=10)$ & $10.9(2.93 ; \mathrm{n}=5)$ & 19 & 19 & 15 \\
\hline Jul 2005 & 28 & $18.9(0.54 ; \mathrm{n}=11)$ & $7.9(2.56 ; \mathrm{n}=11)$ & 13 & 13 & 10 \\
\hline Jan 2006 & 44 & $27.1(1.04 ; \mathrm{n}=19)$ & $6.9(3.59 ; \mathrm{n}=19)$ & 30 & 30 & 30 \\
\hline Jul 2006 & 20 & $20.2(0.87 ; \mathrm{n}=8)$ & $5.1(2.17 ; \mathrm{n}=8)$ & 23 & 23 & 22 \\
\hline Feb 2007 & 35 & $24.3(0.88 ; \mathrm{n}=10)$ & $5.3(0.80 ; \mathrm{n}=15)$ & 23 & 22 & 23 \\
\hline Apr 2007 & 12 & $22.9(0.63 ; \mathrm{n}=4)$ & $11.0(1.10 ; \mathrm{n}=4)$ & 5 & 5 & 5 \\
\hline Jul 2007 & 6 & $13.9(0.44 ; \mathrm{n}=4)$ & $3.2(0.50 ; \mathrm{n}=4)$ & 10 & 10 & 10 \\
\hline Jan 2008 & 25 & $25.1(0.77 ; \mathrm{n}=14)$ & $6.7(2.02 ; \mathrm{n}=15)$ & 32 & 32 & 32 \\
\hline Total & 225 & $23.7(3.68 ; \mathrm{n}=92)$ & $7.3(3.04 ; \mathrm{n}=92)$ & 163 & 154 & 155 \\
\hline
\end{tabular}

minimize distortions caused by inclination, with a small $(5 \mathrm{~cm})$ ruler as a scale. After each field expedition, photographs were digitally improved and printed for comparison of the newly obtained facial profiles with the previously catalogued ones. For photo-ID we compared the shape and arrangement of facial scutes. The catalogue was organized according to the individual's number, and the capture's biometric data was written on the back of the picture. In order to consider only potential matches we limited comparison to previously catalogued individuals with CCL about $2 \mathrm{~cm}$ larger and $8 \mathrm{~cm}$ smaller than the turtle being matched. This was done without prior inspection of the artificial tag data (acquired in situ at the moment of the turtle's recapture) of the thus-analyzed individuals. Therefore, it was possible to partially validate the photo-ID method by later comparing its results with the ones obtained by the traditional artificial marking method.

As a considerable number of recaptured turtles were missing at least 1 of the tags, we estimated (1) the proportion of tags lost within $1 \mathrm{yr}$ after tagging, (2) the mean life span of a tag and (3) the probability of tag survival in terms of time after tagging. In this study we classified as lost not only tags not on the turtle at the moment of recapture, but also those retained with identification number illegible due to corrosion. Tags almost falling off, or embedded into the turtle's flipper so that it needed to be removed for reading, were con- sidered as retained even if later replaced. Estimates of tag loss were performed within a Bayesian statistical framework (Gelman et al. 1995, Ellison 1996), assuming an exponential distribution for tag life span and a non-informative prior. These are presented here in the form of posterior probability distributions (see details in Appendix 1). All analyses and visualizations were performed using software R (R Development Core Team 2008).

\section{RESULTS}

Visual comparison of head images showed that the turtles catalogued at Arvoredo Island (Table 3) have particular facial scute patterns of both shape and arrangement, which allow a reliable and easy recognition of individuals (Fig. 2). We consider that the photoID technique described in this work is validated to the extent that it correctly identified all the recaptures already identified in situ by the presence of Inconel tags. Under this premise, we considered as recaptures not only the recaptured individuals already identified by the tags, but also those that were only matched through photo-ID due to loss of both tags. Recaptures identified only through photo-ID included individuals photographed and catalogued during the first expedition $(\mathrm{n}=4)$, as well as individuals that lost both metal tags since their initial tagging $(n=5)$.

Table 3. Chelonia mydas and Eretmochelys imbricata. Biometrics of sea turtles caught at Arvoredo Island. Mean values, as well as range (in parentheses) are shown. CCL = curved carapace length; CCW = curved carapace width; SCL $=$ straight carapace length; SCW = straight carapace width

\begin{tabular}{|lccccc|}
\hline Species & CCL $(\mathrm{cm})$ & CCW $(\mathrm{cm})$ & SCL $(\mathrm{cm})$ & SCW $(\mathrm{cm})$ & Mass $(\mathrm{kg})$ \\
\hline C. mydas & $50.1(32.0-83.0)$ & $30.8(30.0-77.0)$ & $47.9(30.6-79.5)$ & $38.8(26.0-64.5)$ & $18.2(4.0-75.0)$ \\
E. imbricata & $44.1(36.0-59.5)$ & $39.3(32.0-51.0)$ & $42.0(34.5-57.0)$ & $32.3(25.5-42.0)$ & $10.75(5.0-22.5)$ \\
\hline
\end{tabular}



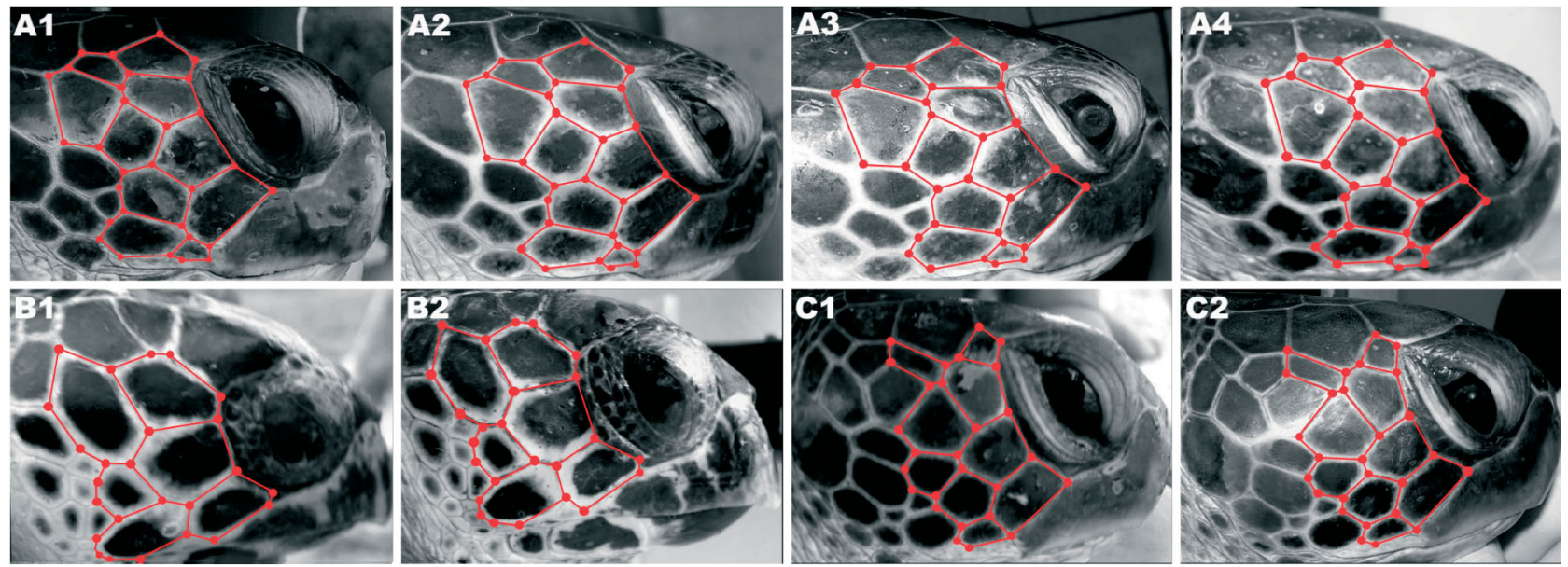

Fig. 2. Chelonia mydas and Eretmochelys imbricata. Four profiles of the same individual (A1 to A4) at different time intervals; and 2 other individuals (B1, B2 and C1, C2) identified photographically. Time intervals between photographs A1 and A2, A1 and A3, and A1 and A4 were 194, 572 and 906 d, respectively; intervals between photographs B1 and B2 and C1 and C2, were 708 and $909 \mathrm{~d}$, respectively. Some scute arrangements are outlined in red for a better view of the individual patterns. Turtles A and C are C. mydas and Turtle B is E. imbricata

Out of 157 captures of Chelonia mydas and 6 of Eretmochelys imbricata, a total of 35 recaptures of 28 individuals of the former species and 2 recaptures of an individual of the latter species were recorded. Of the identified recaptures, 24 were recognized by the 2 methods (photo-ID plus tags), 9 only by photo-ID and 4 only by artificial marking (tags). These latter were 3 individuals not photographed at recapture or which had no previously catalogued photo and 1 individual stranded on the coast of São Paulo state (southeastern Brazil), reported by the Projeto Tamar-ICMBio. Time intervals between initial marking and last recapture varied from 126 to $1046 \mathrm{~d}$.

Over this 3 yr study, data from 66 artificial tags were available for the development of a new tag-loss estimation method. Despite the short study period, metal tag loss was high. Out of 24 tags attached BS, 14 (58.3\%) were lost, and out of the 42 tags attached in the PS position, only $4(9.5 \%)$ were lost. Although our data indicate that the PS position results in reduced loss, it is necessary to note that this type of application is more recent and therefore the observed time intervals are shorter in comparison to the BS position. Out of 48 tags retained on the flippers at recapture, most were completely incrusted by barnacles, bivalves, filamentous algae and macrophytes, and 8 were in an advanced state of corrosion or imbedded in the turtle's swollen tissue, being thus removed for application of new tags (Fig. 3).

Considering that our data indicate distinct tag loss rates for the 2 positions (BS and PS), we present the proposed estimates separately for each situation. The posterior distribution for the proportion of lost tags over a period of $1 \mathrm{yr}$ yielded a mean of 0.54 with a $95 \%$ credibility interval (Cr. I. 95\%) of 0.34 to 0.72 for BS and mean of 0.13 (Cr. I. $95 \%$ : 0.04 to 0.25 ) for PS with a mean life span of 499 (Cr. I. 95\%: 287 to 878) and 3204 d (Cr. I. $95 \%$ : 1269 to 8074), respectively. Posterior distributions of tag survival probability (mean and $95 \%$ CI) as function of time in days since tag application can be seen in Fig. 4.

\section{DISCUSSION}

Although facial profiles had already been used for underwater individual identification in a study of Hawaiian green turtles (Bennett el al. 2000), facial scute shape and arrangement patterns to systematically photo-ID cheloniid turtles is used and validated here for the first time. Our study demonstrates that the clear differences in facial scute patterns can be reliably employed for recognition of individuals from a population over a given period. We recorded no change in the arrangement and shape of facial scutes over at least $1046 \mathrm{~d}$, and the individual differences in these patterns are so great that with this method we were able to distinguish correctly all individuals caught at Arvoredo Island. Long-term studies, involving other cheloniid populations and species, can validate the value of facial scutes as natural marks for continuous individual recognition throughout their long lives.

Photo-ID automation for sea turtles would make the method less costly, more practical and much faster, thus encouraging its application in long-term studies, which usually involve a high number of photographs and a group of researchers. In order to develop an automated individual recognition program, choosing 

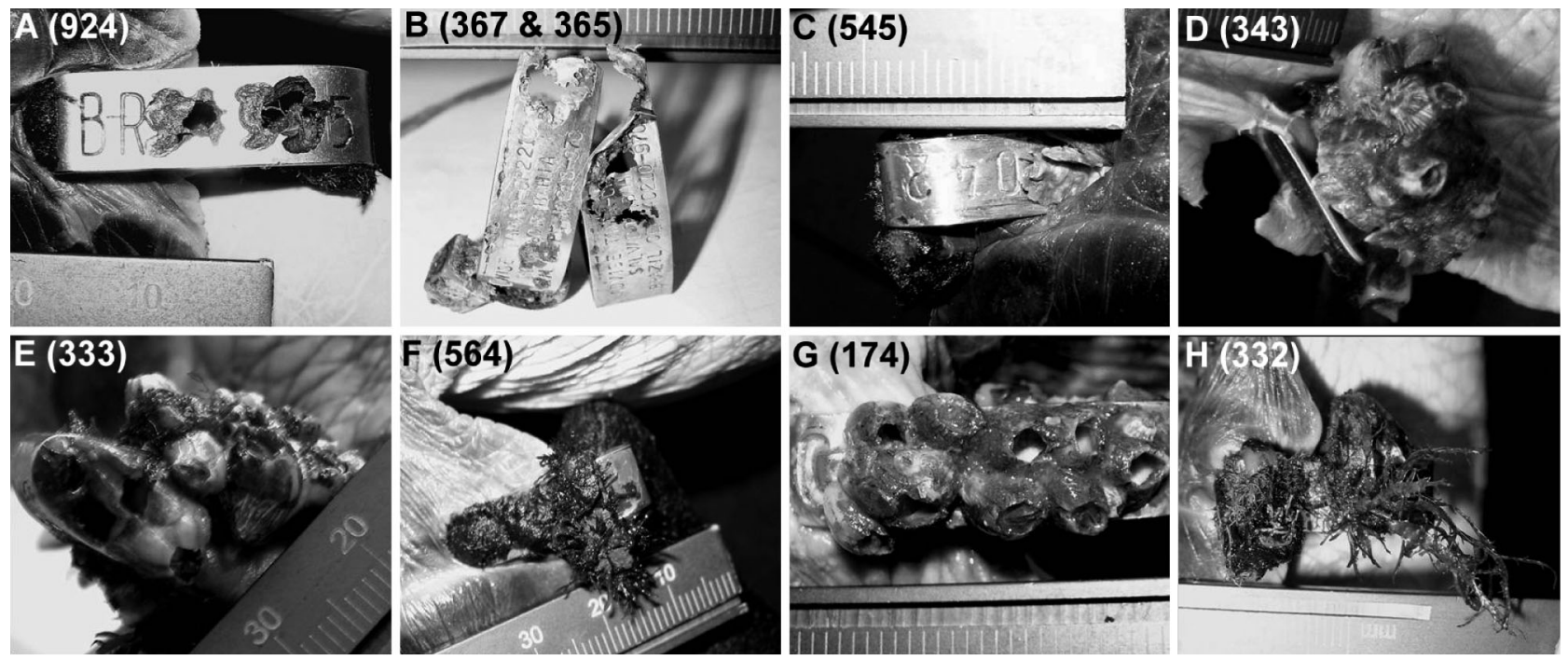

Fig. 3. Examples of tag anomalies noted in this study: $(A, B)$ corroded, $(C)$ embedded in the turtle's tissue, (D) torn and (E-H) fouled. Age (d) of each tag is given in parentheses. Only Tag A was considered as lost in tag loss estimations. Tag D was replaced and all others were cleaned

well the features to be matched is of paramount importance, as they should be easy to see and photograph (Speed et al. 2007). This information should be extracted from a suitable photo and quantified in a way independent of factors such as camera distance and viewing angle (Kelly 2001). Afterwards, the information extracted from several photos should be compared using a measure of similarity among them. All potential matches should be presented to the user for inspection and final decision of reliability. The elaboration of an automated process for the photo-ID technique described here may start with the selection of 3 'fixed points' with a known relative position (e.g. eye, nostril, and mouth) so that any other point of interest may be represented in an affine coordinate system. The intersection points formed by the lines that divide some facial scutes (see Fig. 2) are a potential feature to be matched, since they seem to form a unique mosaic for each individual. Considering that stable point patterns are common in wildlife, a growing number of recognition programs have been developed based on the extraction of these features. The automated spotrecognition program $\left(\mathrm{I}^{3} \mathrm{~S}\right)$ is a software that provides a freely available method for application (Speed et al.
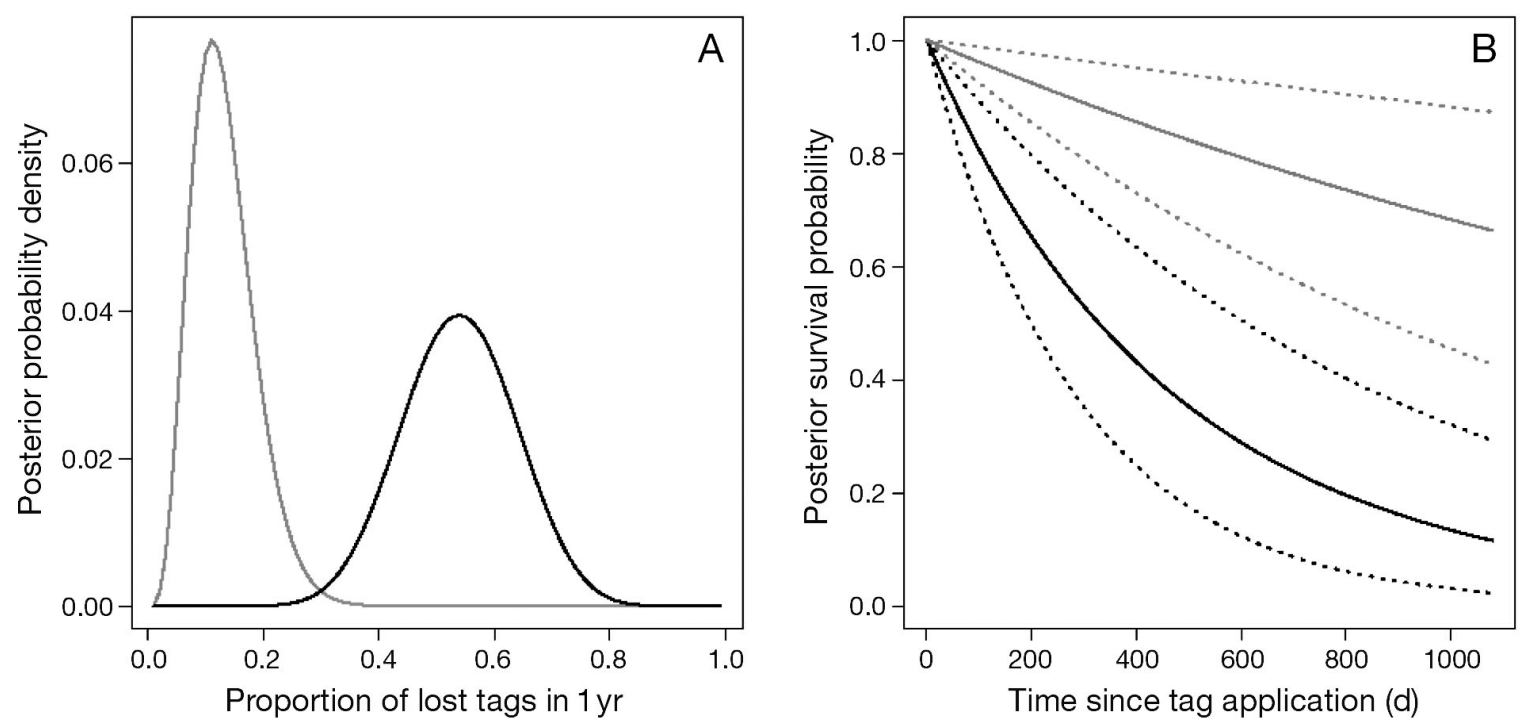

Fig. 4. Posterior distribution for the proportion of lost tags over a period of (A) 1 yr and (B) average life-span of an individual tag for tag attached to positions between scales (black) and pre-scales (gray) 
2007) and could therefore be tested for the automation of chelonian photo-ID based on scute patterns.

When the application of sea turtle photo-ID on a large databank becomes possible, it will be very useful for examining associations between individuals at different spatial and temporal scales. A worldwide database formed through partnership among different projects would be extremely important for such a goal. Moreover, incentive campaigns could be launched so that fishermen, divers, or any people who might find a sea turtle, are able to supply photographs adequate for photo-ID.

An important aspect of the photo-ID technique is the possibility of identifying individuals with no need of capture and/or handling for marking with tags or passive integrated transponder (PIT, see Balazs 1999). The problems associated with capture, handling and tagging of marine turtles have been the subject of few studies and appear to be difficult to measure (Broderick \& Godley 1999). Among problems already reported in the literature are elevated corticosteroid levels after capture (Valverde et al. 1996), possibility of tagging wounds being an infection source in captive-reared turtles (Witzell 1998), alteration of nesting behavior (Broderick \& Godley 1999) and, probably the most important, the possibility that turtles with no tags are more capable of escaping from fishing nets. This latter view is supported by interviews with fishermen, studies with experimental nets and records of black turtles Chelonia mydas agassizii that likely become entangled in fishing nets due to their plastic flipper tags (Nichols \& Seminoff 1998).

In non-invasive studies, such as that of Bennett et al. (2000), underwater photographs of facial scutes could be used for identification of individuals, adding this important information. In a study of white rhinoceroses Ceratotherium simum, when a given rhino's footprint identity was assigned, it was fed into a database along with GPS data and any other visual information gathered (Alibhai et al. 2008). These data could then be imported into a mapping tool to plot rhino distribution and ranges. By analogy, if divers tow a portable GPS device (see technique in Roelfsema et al. 2007), the acquisition of sighting position would also make possible the acquisition of home-range and habitat use information for marine turtles. Of course, for areas with clear waters, where observational studies are more common (e.g. Booth \& Peters 1972, Houghton et al. 2003, Sazima et al. 2004, Grossman et al. 2006), the efficiency of underwater photo-ID would be much higher than in areas with relatively low water visibility such as the Arvoredo Marine Biological Reserve (see Table 2).

Additionally, when used as an alternative method in tagging programs, such as described here or in
McDonald \& Dutton (1996), photo-ID should provide more accurate information. Most studies quantifying sea turtle tag loss have estimates restricted to artificial tag data from individuals that still retain at least 1 mark at the time of recapture; thus, turtles that lost all applied tags before recapture would be incorrectly categorized as new, leading to an underestimation of tag loss rates (van Dam \& Diez 1999). Some researchers relied on scars to identify turtles that have lost all tags, but Bjorndal et al. (1996) demonstrated that this method may not be reliable, as shown by a $37 \%$ detection of lost tags by tag scars. The overestimation of tag retention is a common problem in sea turtle research (McDonald \& Dutton 1994) and low tag retention could help explain why the majority of turtles tagged on nesting beaches are only seen once (Mrosovsky \& Shettleworth 1982).

If the photo-ID described here is validated as a longterm recognition method, tag loss problems will be minimized and improved population dynamics studies may be developed. In the case of application of photoID in nesting beaches, the possible stress due to camera flashes would require further evaluation. Campbell (1994) recorded a shortening in nest covering time when green turtles were subjected to several flashes from photography whilst nesting in Costa Rica. However, the benefits of knowledge gained from this method (i.e. technique validation for adults and improved estimations for tag loss and inter-nesting periods) may perhaps justify such stress.

Despite the low sample size ( $N=66$ recovered tags) and short study period ( $3 \mathrm{yr}$ ), we were able to quantify the influence of factors on the magnitude of tag loss at Arvoredo Island (Fig. 4). Differently from conventional tag loss estimates, the Bayesian model applied here (see Appendix 1) uses information based on continuous time since each individual tagging. This type of model uses tag loss information more efficiently than conventional estimates and is therefore able to produce reasonably precise estimates for comparatively small sample sizes. The use of estimates such as these at the initial stages of a tagging program would be of great advantage for an early evaluation of performance and adjustment in tagging protocol, whose optimum is apparently particular to each research (Bjorndal et al. 1996, Bellini et al. 2001).

Tags attached in the PS position have a longer life span than those attached in the BS position (Limpus 1992). However, the great difference found between types PS and BS in our study is probably a consequence of the decrease in distance between tag end and flipper edge in the PS position. The change in this distance could have promoted a greater resistance to tearing by tag weight increase due to the presence of a wide variety and high biomass of fouling organisms on and in the 
tag. The main evidence for this greater resistance was the increase in number of retained tags completely covered with epibionts in recaptures with PS tags and the observation of various v-shaped scars typical of tearing in BS tags. Despite the higher life span of PS tags, an additional problem occurred, possibly due to this decrease in distance; some tags were embedded in the turtle's swollen tissue so that removal for number reading was necessary. This problem, added to high biofouling, causes a substantial difference in tag visibility. Some demographic estimates that utilize recovered tag data consider tags to have equal probabilities of being noticed. This may be a safe assumption when a trained person systematically inspects a turtle. However, if recovered tags are reported by someone unaware of tagging programs, such as fishermen, the occurrence of non-reported retrieved marks may be a function of the tags' visibility (Mrosovsky \& Shettleworth 1982).

Although unexpected for this material type, Inconel tags in our study showed a highly corroded state for some of the recoveries. This anomaly may also be an important cause for high rate of tag loss at Arvoredo Island. Balazs (1982) described corrosion of Monel tags as common, but Inconel tags are theoretically less susceptible to this process. Bellini et al. (2001) indicate tag corrosion, particularly in the locking mechanism, as the main cause of the failure of Monel tags put on juvenile hawksbill turtles at Fernando de Noronha Archipelago, off northeastern Brazil. These latter authors estimated a probability of 0.57 of tag loss within $1 \mathrm{yr}$ after tagging with Monel tags. However, for Inconel tags, the same authors found a much lower tag loss level, with a probability of 0.049 within 1 yr after tagging and an average durability of $851 \mathrm{~d}$, and attribute the success of this tag type to its resistance to corrosion. In comparison, our estimated tag loss probability within 1 yr after tagging $\left(\theta_{365}\right)$ for the best type of application is 0.13 , with an average life-span of $3204 \mathrm{~d}$. At first sight it seems that our higher loss probability could be associated with a smaller life span. In fact, the estimate of Bellini et al. (2001) underestimates average durability since it ignores the fact that their data are censored by the maximum time between tag applications and data analysis.

The unexpected corrosion of Inconel tags in our study may indicate higher corrosive conditions at the study area, when compared to other areas where similar estimates were calculated for this tag type. The rate of corrosion is not always correlated with the total time a tag is attached. Some possible factors may include the composition and temperature of the water, diet of the turtle, serum chemistry, as well as small but conceivably important differences in the composition of the alloy used and the way the tags are manufactured (Balazs 1982). Underwater observations of green tur- tles foraging at shallow sites $(0.5$ to $1.0 \mathrm{~m})$ at Arvoredo Island indicate that the abrasion of tags against rocky bottom (authors' pers. obs.) may also be an additional cause for high tag loss rate.

Photo-ID of various animal types is a common methodology in field studies, and sea turtles should not be an exception. When considering the high and variable tag loss rates in sea turtles, the intrinsic value of a recapture and the effects of manipulation, the importance of the photo-ID method described here becomes evident. Despite the fact that photo-ID was used here for juvenile Chelonia mydas and Eretmochelys imbricata only, we believe that this method may be applied to all species of the Cheloniidae during most, if not all, phases of their life cycles. We suggest that photo-ID be used not only as a complement to artificial marking in mark-recapture studies, but also for the development of non-intrusive studies involving animal sightings and re-sightings. The validation of photo-ID as a suitable path in individual recognition would decrease the need for intentional capture of cheloniid turtles, reduce bias in behavioral studies, increase the number of catalogued individuals (for a potentially higher time interval), and thus provide easily obtainable data for studies in nesting beaches and foraging areas.

Acknowledgements. We thank Pata da Cobra Diving and the Brazilian Navy for logistic support during field expeditions, research staff for work assistance in the Arvoredo Island, T. Gandra for providing a map of the study area, A. Grossman and P. Mendonça for training to capture sea turtles and management techniques, and E. Secchi for comments on the manuscript. The authors received financial support from CNPq - Brazil.

\section{LITERATURE CITED}

Alibhai SK, Jewell ZC, Law PR (2008) A footprint technique to identify white rhino Ceratotherium simum at individual and species levels. Endang Species Res 4:205-218

Balazs G (1982) Factors affecting the retention of metal tags on sea turtles. Mar Turtle Newsl 20:11-14

Balazs G (1999) Factors to consider in the tagging of sea turtles. In: Eckert KL, Bjorndal KA, Abreu-Grobois FA, Donnelly $M$ (eds) Research and management techniques for the conservation of sea turtles, Vol 4. IUCN/SSC Marine Turtle Specialist Group, Blanchard, p 101-109

Bellini C, Godfrey MH, Sanches TM (2001) Metal tag loss in wild juvenile hawksbill sea turtle (Eretmochelys imbricata). Herpetol Rev 32:172-174

Bennett P, Keuper-Bennett U, Balazs GH (2000) Photographic evidence for the regression of fibropapilloma afflicting green turtles at Honokawai, Maui, in the Hawaiian Islands. In: Kalb H, Wibbels T (eds) Proc 19th Annu Symp Sea Turtle Biol Cons NOAA Tech Memo NMFS-SEFSC443:37-39

Bjorndal KA, Bolten AB, Lagueux CJ, Chaves A (1996) Probability of tag loss in green turtles nesting at Tortuguero, Costa Rica. J Herpetol 30:566-571

Booth J, Peters JA (1972) Behavioral studies on the green turtle (Chelonia mydas) in the sea. Anim Behav 20:808-812 
Broderick AC, Godley BJ (1999) Effect of tagging marine turtles on nesting behaviour and reproductive success. Anim Behav 58:587-591

Burghardt T, Thomas B, Barham PJ, Calic J (2004) Automated visual recognition of individual African penguins. In: 5th International Penguin Conference (IPC04), Ushuaia, Tierra del Fuego

Campbell GL (1994) The effects of flash photography on nesting behaviour of green turtles (Chelonia mydas), Tortuguero, Costa Rica. In: Bjorndal KA, Bolten AB, Johnson DA, Eliazar PJ (eds) Proc 14th Annu Workshop Sea Turtle Biol Cons NOAA Tech Memo NMFS-SEFSC-351:23-24

Castro ALF, Rosa RS (2005) Use of natural marks on population estimates of the nurse shark, Ginglymostoma cirratum, at Atol das Rocas Biological Reserve, Brazil. Environ Biol Fishes 72:213-221

Ellison A (1996) An introduction to Bayesian inference for ecological research and environmental decision-making. Ecol Appl 6:1036-1046

Frisch AJ, Hobbs JA (2007) Photographic identification based on unique, polymorphic colour patterns: a novel method for tracking a marine crustacean. J Exp Mar Biol Ecol 351:294-299

Gelman A, Carlin JB, Stern HS, Rubin DB (1995) Bayesian data analysis. Chapman \& Hall, London

Gherardi DFM (2004) Community structure and carbonate production of a temperate rhodolith bank from Arvoredo island, southern Brazil. Braz J Oceanogr 52:207-224

Gope C, Kehtarnavaz N, Hillman G, Würsig B (2005) An affine invariant curve matching method for photo-identification of marine mammals. Pattern Recognit 38:125-132

Grossman A, Sazima C, Bellini C, Sazima I (2006) Cleaning symbiosis between hawksbill turtles and reef fishes off northeast Brazil. Chelonian Conserv Biol 5:284-288

Hammond PS, Mizroch SA, Donovan GP (1990) Individual recognition of cetaceans: use of photo-identification and other techniques to estimate population parameters. International Whaling Commission, Cambridge

Houghton JDR, Callow MJ, Hays GC (2003) Habitat utilization by juvenile hawksbill turtles (Eretmochelys imbricata, Linnaeus, 1766) around a shallow water coral reef. J Nat Hist 37:1269-1280

Kelly MJ (2001) Computer-aided photograph matching in studies using individual identification: an example from
Serengeti cheetahs. J Mammal 82:440-449

Limpus CJ (1992) Estimation of tag loss in marine turtle research. Wildl Res 19:457-469

Markowitz TM, Harlin AD, Würsig B (2003) Digital photography improves efficiency of individual dolphin identification. Mar Mamm Sci 19:217-223

McDonald DL, Dutton PH (1994) Tag retention in leatherback sea turtles (Dermochelys coriacea) at Sandy Point, St. Croix, USVI. In: Schoroeder BA, Witherington BE (eds) Proc 13th Annu Symp Sea Turtle Biol Cons NOAA Tech Memo NMFS-SEFSC-34:253

McDonald DL, Dutton PH (1996) Use of PIT tags and photoidentification to revise remigration estimates of leatherback turtles (Dermochelys imbricata) nesting in St. Croix, U.S. Virgin Islands, 1979-1995. Chelonian Conserv Biol $2: 148-152$

Mrosovsky N, Shettleworth SJ (1982) What double tagging studies can tell us. Mar Turtle Newsl 22:11-15

Nichols WJ, Seminoff JA (1998) Plastic 'Rototags' may be linked to sea turtle bycatch. Mar Turtle Newsl 79:20-21

R Development Core Team (2008) R: a language and environment for statistical computing. R Foundation for Statistical Computing, Vienna. Available at: www. R-project.org

Roelfsema CM, Phinn S, Joyce K (2007) A manual for using GPS referenced digital photo transects to validate benthic cover maps. Centre for Remote Sensing and Spatial Information Science, University of Queensland, Brisbane

Sazima C, Grossman A, Bellini C, Sazima I (2004) The moving gardens: reef fishes grazing, cleaning, and following green turtles. Cybium 28:47-53

Speed CW, Meekan MG, Bradshaw CJA (2007) Spot the match: wildlife photo-identification using information theory. Front Zool 4:1-11

Valverde RA, Provancha JA, Coyne MS, Meylan A, Owens DW, McKenzie DS (1996) Stress in sea turtles. In: Keinath JA, Barnard DE, Musick JA, Bell BA (eds) Proc 15th Annu Symp Sea Turtle Biol Conserv NOAA Tech Memo NMFSSEFSC-387:326-329

van Dam RP, Diez CE (1999) Differential tag retention in Caribbean hawksbill turtles. Chelonian Conserv Biol 3: $225-229$

Witzell W (1998) Messages in bottles. Mar Turtle Newsl $80: 1-3$ 
Appendix 1. Estimate of tag loss in sea turtles with use of Bayesian inference

\section{The problem}

Conventional survival models do not apply directly to sea turtle mark-recapture data, considering that the exact times between tag application and removal are unknown. Available information, besides being restricted to the presence or absence of the tag on recapture, is also censored by the maximum time between tag application and data analysis or tag removal from the animal due to poor retention or lack of readability.

Recaptures of turtles previously photo-identified and artificially marked can provide different types of data, depending on the life history of their tags:

Scenario I: If the tag is still retained, there is the number of days between tagging and most recent recapture of the $\operatorname{tag} i\left(C_{i}\right)$.

Scenario II: If the tag has already been lost, there is the number of days between tagging and the most recent recapture of the tag $i\left(c_{i}\right)$, and the number of days between tagging and first recapture without $\operatorname{tag} i\left(s_{i}\right)$. When the turtle had already lost a tag on its first recapture, $C_{i}$ is zero; such value does not provide any information for the estimations. From a total of $n$ tags applied to recaptured sea turtles, $m_{c}$ provide information for Scenario I and $m_{s}$ information for Scenario II, so that $n=m_{c}+m_{s}$. With such information, various questions can readily be answered in a Bayesian context. In this study, the questions of interest were: (1) What is the proportion of tags lost after 1 yr of application? (2) What is the expected life span for the artificial tag? (3) What is the survival probability of a tag in function of the time passed after its application?

\section{The statistical model}

Estimates were performed with Bayesian analysis (Ellison 1996), to supply direct responses to the questions formulated above. We start with a probabilistic model for number of days between tag application and loss, $X$. Supposing that $X$ follows an exponential model with parameter $\mu$, such that the expected number (mean) of days until tag loss is denoted as:

$$
E(X)=\mu^{-1}
$$

And, for $\mu>0$ e $X>0$ :

$$
f(x)=\mu \mathrm{e}^{-\mu x}
$$

Although the values of $X$ are not directly observable, some probabilistic relationships to $C_{i}$ and $s_{i}$ and which are relevant to the estimation of $\mu$ can be established.

If the ith tag is still present (Scenario I) at the most recent recapture event, we have:

$$
P\left(X_{i}>C_{i}\right)=\mathrm{e}^{-\mu c_{i}}
$$

If the ith tag has already been lost (Scenario II), we have:

$$
P\left(X_{i}<s_{i} \mid X_{i}>C_{i}\right)=\frac{P\left(c_{i}<X_{i}<s_{i}\right)}{P\left(X_{i}>C_{i}\right)}=1-\mathrm{e}^{-\mu\left(s_{i}-C_{i}\right)}
$$

Hence, assuming independence between tags, the likelihood function for $\mu$ based on the available data is:

$$
L(\mu)=\mathrm{e}^{\left(-\mu \Sigma_{i=1}^{m_{C} c_{i}}\right)} \times \prod_{j=1}^{m_{s}}\left(1-\mathrm{e}^{-\mu\left(s_{i}-c_{i}\right)}\right)
$$

\section{Prior probability distribution for $\mu$}

We define $\theta_{k}$ as the 'probability of losing the tag within a period of $k$ days'. This probability is a function of $k$ and the parameter $\mu$ from the exponential probability model.

$$
\theta_{k}=P(X \leq k)=1-\mathrm{e}^{-\mu k}
$$

Establishing a prior on $\theta_{k}$ is simple, considering that we have a better understanding of this parameter and mostly because it is limited to a $[0,1]$ interval. The non-informative distribution on $\theta_{k}$ is the uniform distribution. It can be shown, via transformation of variables, that this is equivalent to establishing as prior for $\mu$ an exponential distribution with parameter $k$. That is:

$$
p(\mu)=k \mathrm{e}^{-\mathrm{k} \mu}
$$

Considering that the uniform distribution on the unit interval $[0,1]$ is a particular case of the beta family of distributions, there is an obvious manner in which generalizations of this prior are possible. Therefore, if we start with a prior for $\theta_{k}$ as a beta distribution with parameters $a$ and $b$, then the corresponding prior for $\mu>0$ will be:

$$
p(\mu)=\frac{\Gamma(a+b) k}{\Gamma(a) \Gamma(b)}\left(1-\mathrm{e}^{-\mu k}\right)^{a-1}\left(\mathrm{e}^{-\mu k}\right)^{b}
$$

\section{Posterior probability distribution}

The posterior distribution for $\mu$ expresses the uncertainties on this parameter conditioned to data $D$, and is obtained proportional to the product between likelihood and prior according to Bayes theorem. That is, given:

$$
D=D_{\mathrm{I}} \cup D_{\mathrm{II}}=\left[c_{i}, i=1_{1} \ldots, m_{c}\right] \cup\left[\left(c_{j}, s_{j}\right), j=1, \ldots, m_{s}\right]
$$

the posterior distribution for $\mu$ is

$$
p(\mu \mid D) \propto L(\mu) p(\mu)
$$

Once this distribution is known, we can also obtain the posterior distribution for any transformation. Here, the interest is in (1) $\theta_{365}=1-\mathrm{e}^{-365 \mu}$, the probability of a tag being lost or unreadable after $1 \mathrm{yr}_{;}(2) \mu^{-1}$, the number of expected days until tag loss; and (3) $1-\theta_{k}=\mathrm{e}^{-\mu k}$, the probability of tag survival after $k$ days.

A Bayesian survival curve can be constructed when overlapping in the same graph the posterior probabilities of 1 $\theta_{k}$ calculated for increasing $k$ values. We utilized a sampling importance resampling algorithm (Gelman et al. 1995) in order to obtain simulated samples of the posterior distribution of $\mu$. For every $\mu$, we calculated $\theta_{k}$, obtaining in this manner the corresponding posterior distribution. Through Monte Carlo methods, we obtained the mean (predictive probability) and a $95 \%$ CI for distinct $k$ values. 